\title{
The Socio-Economic Impact of Fascioliasis Disease in Nandi Central District, Kenya
}

\author{
Mutai Paul. \\ MSc Student, Department of Animal Science, University of Eldoret \\ Ngaira V. M. \\ Lecturers, Department of Animal Sciences \\ Baraton College of Animal Health and Production \\ University of Eldoret and Maseno University \\ Kios D.K \\ Lecturer, Department of Animal Science \\ University of Eldoret, Kenya

\section{Lilian Akinyi Ooko}

\begin{abstract}
The study was carried out in Nandi Central in Nandi County to evaluate the economic impact of fascioloasis disease and it's prevalence amongst cattle, sheep and goats in three divisions namely Kapsabet, Kosirai and Kilibwoni. The named divisions have a sizeable coverage by papyrus a swab which is home to the snail species lymnae trancatum and lymnae trancatula which are vectors of the disease as the intermediate host.The research design was a survey and sampling technique used was purposeful sampling. Secondary data was collected from Kapsabet District Veterinary Office on the number of condemned liver from the cattle, keep and goats and financial losses were computed based in the price of the respective livers of each species and data analysis was done using SPSS Version 16. Mean separation was done using L.S.D $(P<0.05)$. A total of 1106 livers were condemned comprising of 721 (Bovine Spp); 342 (Ovine Spp) and 43 (Caprine Spp), which translated to arrival financial losses of 823,060 .There was significant difference of fascioliasis between Kosirai and both Kilibwoni and Kapsabet. Bovine Spp had the highest incidence followed by Ovines Spp and finally Caprine Spp. It was also found that there was a positive correlation between the incidents rate and livers condemned and the usually high rainfall seasons of around March-October.
\end{abstract}

Keywords: Fascioliasis, Economic impact, Nandi District

\section{INTRODUCTION}

Fascioliasis is an endemic parasitic infection of the liver of wild domestic ruminant's i.e cattle, sheep and goats, and caused by trematodes of the genus Fasciola (liver flukes) (Gracey et al., 1992). It is carried by two species namely Fasciola hepatica and Fasciola gigantic and transmitted by the snail vectors of family the Lymnae trancatum and Lymnae trancatula which inhabit swampy areas (Torgerson et al.,1999).This habitat is very expansive in swampy areas of Nandi District of Nandi County in Western Kenya. This disease causes huge economic loses in livestock due to mortalities, abortions, retarded growth, reduced meat and milk production, condemnation of infected livers, emaciation and cost of animal treatment (Gracey \& Collins 
,1992). Nandi District is well endowed with good climate that favours livestock production but the realization of optimal livestock productivity is confounded by the prevalence of this fatal disease (MoA, 2010). Theory and practice have shown that the most effective way to break the Fasciola life cycle is by eliminations both the flukes present in grazing animals and the source of infection on the pasture.

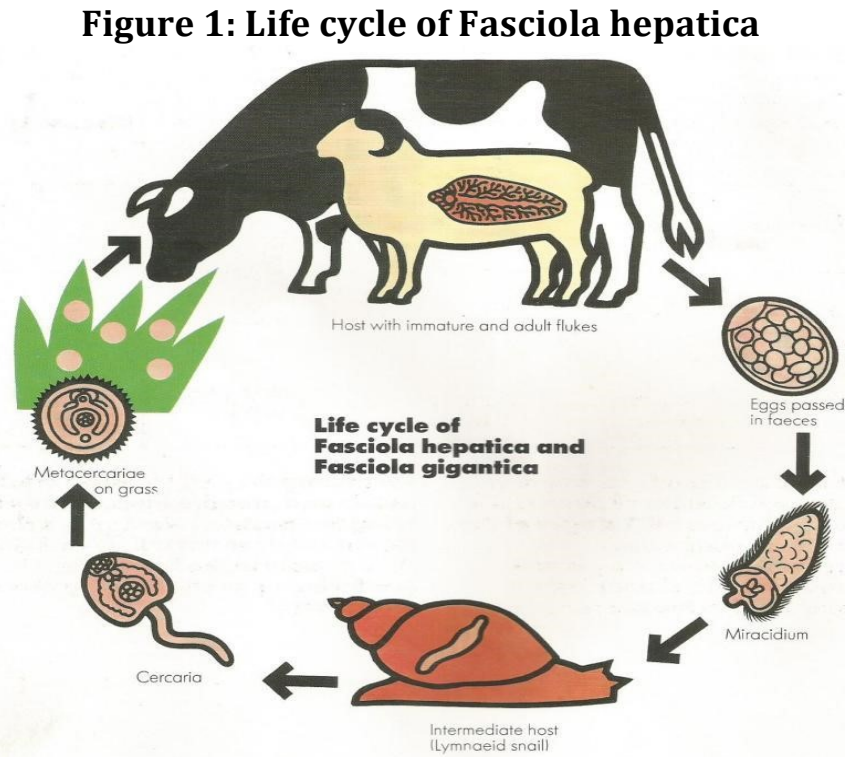

Source: (Amor \& Bogan, 1982)

With respect to Figure 1 above, the infective cysts (metacercariae) on the pasture come from the intermediate host (snail) which is always associated with wet or marshy areas. Amor et al., 1982 outlined measures to reduce the exposure of livestock to snail invested areas including drainage, fencing, and use of molluscides will help in control of fluke disease in marshy areas. However the key to successful control of fluke disease is elimination of both immature and mature flukes already present in the animals (Amor \& Bogan, 1982).

This research aimed at bringing to light the huge financial losses due to liver condemnation and to recommend effective control measures based on work already done in terms of effective drugs for the control of fascioliasis.

\section{Problem statement}

Nandi Central District is a major contributor to the livestock production in Nandi County. However, the presence of vast swampy areas in the area predisposes cattle sheep and goats to fascioliasis disease, due to the presence of the snail habitat.The snail in the swamps transmits the fatal disease and farmers incur financial losses due to the presence of the disease. Affected livers from the cattle sheep and goats are contaminant and latent production, reproductive and mortality loses confounds the adverse economic effects due to this disease.

\section{Justification}

Globally losses in animal productivity due to fascioliasis disease were conservatively estimated to be over US\$ 3.2 billion per annum (Spithil et al., 1999). Farmers in Nandi Central District by virtue of the presence of the expansive snail habitat swamps are definitely incurring huge financial losses due to this disease and there is need to investigate the extend of the economic losses and the prevalence of the disease and recommend effective, efficient and sustainable control measure against the disease so as to make livestock productivity in the area profitable and improve the standard of living of the farmers. Beside financial loses there are also latent 
production, and reproductive loses, notwithstanding the pre-disposition to fatal secondary infectious necrotic hepatitis in sheep and liver cirrhosis in cattle.

\section{General objective}

To investigate the socioeconomic impact of fascioliasis disease in Nandi District, Nandi County.

\section{Specific objectives:-}

1. To establish the actual financial losses due to fascioliasis in cattle, sheep and goats in Nandi Central District.

2. To determine the prevalence rate of fascioliasis among species affected in Nandi District.

\section{Research Hypothesis}

H0: There are no fascioloasis cases among Bovine spp, Caprine spp. and Ovine spp. in Nandi District.

H0: There are no financial losses incurred by livestock farmers to fasciolisis in Nandi

District.

\section{Study sites}

\section{MATERIAL AND METHOD}

The survey was carried out in Kapsabet, Kosirai, and Kilibwoni Divisions of Nandi Central District, Nandi County in Kenya. This area is bound by the Equator to the South and extends Northwards to latitude $0034^{\prime} \mathrm{N}$. The Western boundary extends to Longitude $34045^{\prime} \mathrm{E}$, while the Eastern boundary extends to Longitude $35025^{\prime} \mathrm{E}$. The district covers an area of 2,884.22 $\mathrm{Km} 2$ with temperatures ranging from $15^{\circ} \mathrm{C}$ to $26^{\circ} \mathrm{C}$ and rainfall of between $1,200 \mathrm{~mm}$ and $2,000 \mathrm{~mm}$ per annum.

\section{Sample Size and Sampling technique}

A total of 1160 livers were condemned from July, 2012 to July 2013.These livers were obtained from 721 Bovines Spp., 342 Ovines Spp. And 43 Caprine Spp. slaughtered at Kapsabet Slaughter Slab. The data was extracted from the District Veterinary office - Kapsabet records. The data was obtained through purposive sampling from a list of condemned livers; only condemned livers from the endemic areas were targeted.

\section{Data Analysis}

The data set obtained from the secondary data was analyzed using Statistical Package for Social Science(SPSS) Version 16 and mean separation done by Least Significant Difference (LSD) at $\mathrm{P}<0.05$.

\section{The prevalence of fascioliasis}

\section{RESULTS}

The bovines had the highest cases of liver condemned while the Caprine Spp had the lowest number. A great variation of condemned liver 16.87 was reported Bovine Spp while lowest variation 1.14 was in Caprine spp as shown in Table 1 
Table 1: A summary of liver condemned by species

\begin{tabular}{|c|ccc|}
\hline SpactES & Sum & Mean & Std. Deviation \\
\hline Bovine & 721.00 & 18.4872 & 16.87083 \\
\hline Caprine & 43.00 & 1.1026 & 1.14236 \\
\hline Ovine & 342.00 & 8.7692 & 6.68644 \\
\hline Total & 1106.00 & 9.4530 & 12.62352 \\
\hline
\end{tabular}

The highest number of livers were condemned (120) in February and May and the least (30) in November as indicated in Figure 1

Figure 1: Sum of livers Condemned per Month for the whole year

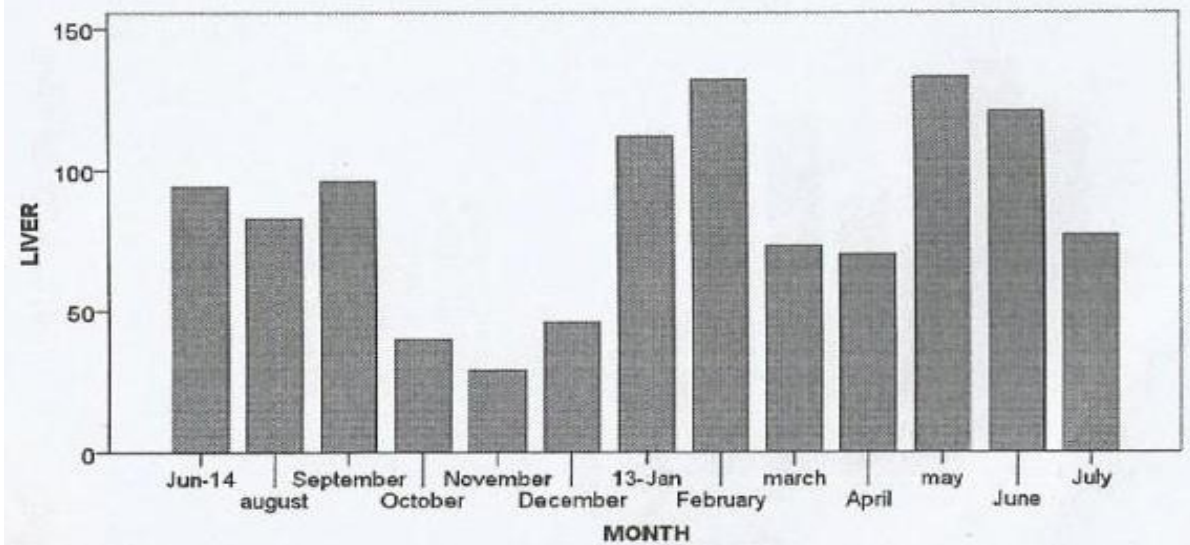

The highest number of livers condemned was in Kosirai while the lowest was reported in Kilibwoni as indicated in Figure 2

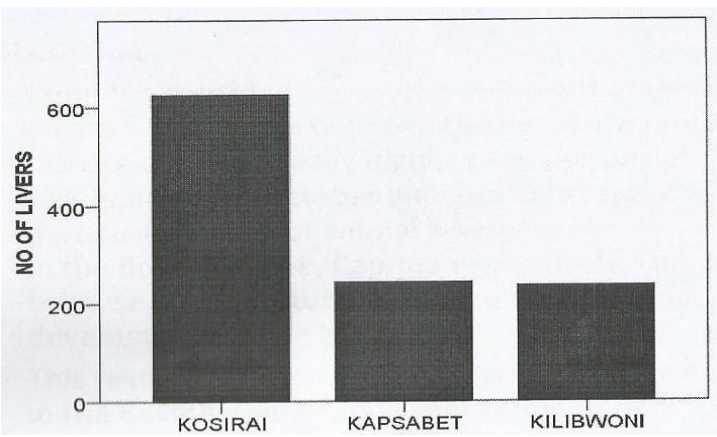

Figure 2: The number of livers condemned in Nandi District over one year

\section{Financial Losses}

The financial losses incurred in from caprine were negligible while over KSh. 600,000 were experienced from Bovine spp as indicated in Figure 3. 


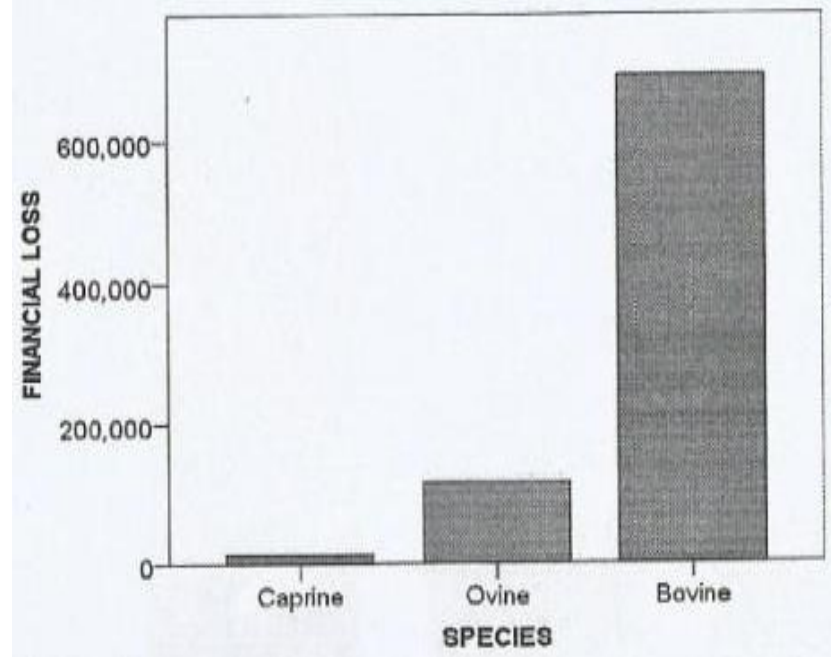

Figure 3: Sum of financial losses due to condemned livers per species for the whole year.

The highest number of losses was recorded in Kosirai Division but the variation between Kilibwoni and Kapsabet divisions was negligible as shown in Figure 4

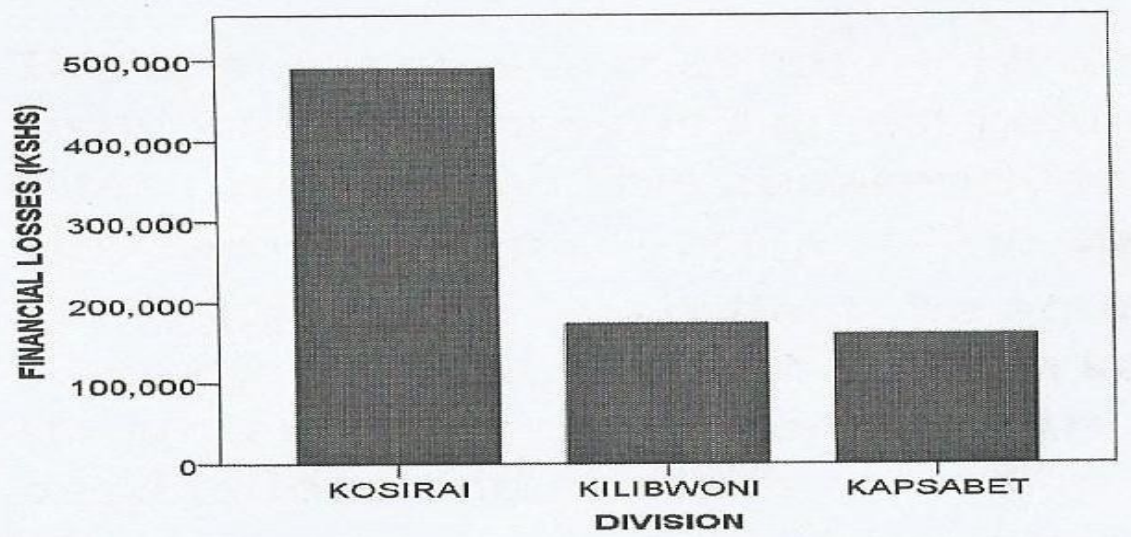

Figure 4: Comparison of financial losses between different divisions

There was no significant difference between Kapsabet and Kilibwoni P $>0.05$ while Kosirai was significantly different $\mathrm{P}<0.05$ from both Kilibwoni and Kapsabet as shown in Table 2

Table 2: Comparison of financial losses between different divisions using Least significant different at 0.05 level of significant Multiple Comparisons

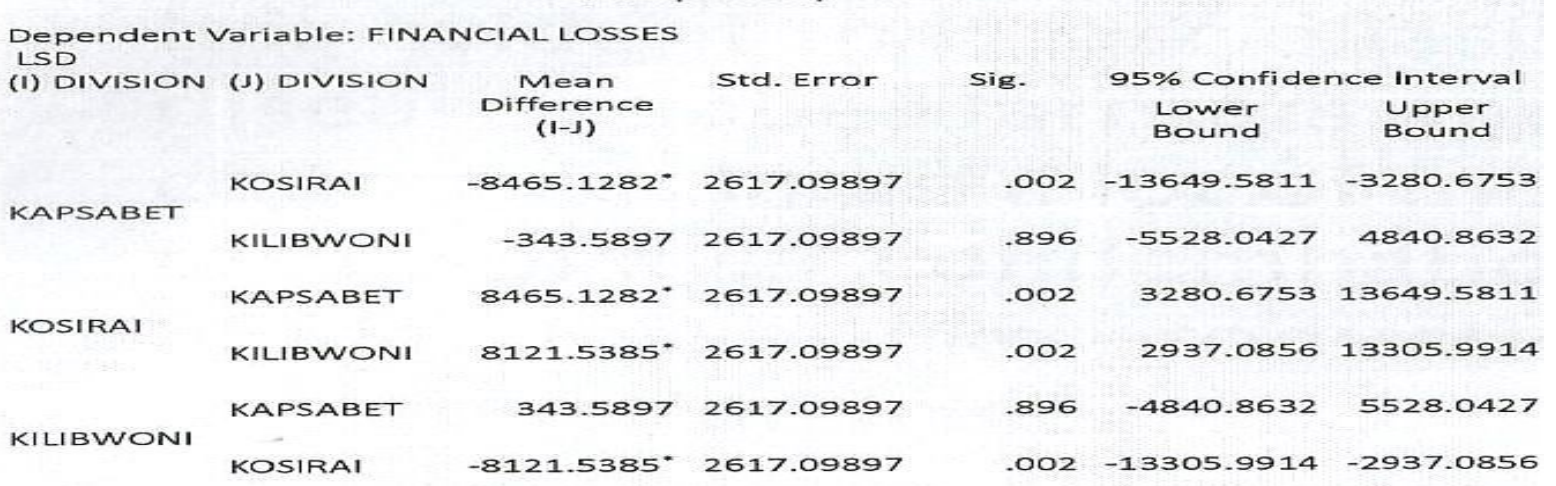




\section{DISCUSSION}

According to the data analysis results indicates that faming in the area incur annual financial loses to the tune of KSh 823,060.00 for all the three species. The Bovines Spp contributes KSh. 692,160.00; Ovines Spp KSh 116,280.00, Caprine Spp Kshs.14, 620. This figure also indicates that farmers in the area prefer to keep cattle, sheep and prevalence follows similar trend. Also the data indicates a positive correlation between the incidence rates of the disease and the usually, high rainfall seasons of April-October in the area. This is because high moisture favours the breeding and the development of the intermediate host (snail).

The disease is also evidently persistent even during dry season of January - March and November -December since the livestock farmers usually graze the animals along the expansive swamp as a tactical grazing management during dry season to alleviate the effect of drought but only to expose their livestock to the disease. The result indicates that Kosirai had the highest financial and prevalence rate followed by Kilibwoni and Kapsabet division respectively, and it correspond to the degree of swamp coverage in the division, There is a significant difference $(\mathrm{P}>0.05)$ among the species in-terms of liver condemnation because Bovines Spp are most reared by farmers.

\section{CONCLUSIONS}

It is evident that Bovines Spp, Ovines Spp. and Caprine Spp. in Nandi District are affected by fascioliasis. Livestock farmers in this district are incurring huge financial loses annually due to prevalence of fascioliasis disease. This loses are confounded by the latent loses in production of milk and meat and the reproductive loses.

\section{RECOMMENDATION}

The district veterinary office Nandi County and the district livestock production office should liase and formulate effective, efficient and sustainable control in measure to reduce the enormous economic losses due to the disease.

\section{References}

Armour, J \& Bogan, J. (1982). Anthelminthic for Ruminants. Br. Vet. J. 138, pg371-382

Baray, J.C. (1981). Control of fascioliasis and paramphistomosis-are there really new concepts and approaches. Australia Veterinary Association. Year book-Australia Advanced Veterinary Science 240-242.

Baray, J.C., Crowfoot, P.D., Strong, M.B. Allison, J.R., Shcellenbaum M., Von Orelli, J.M \& Sarasin, G. (1983). Treatment of immature and mature Fasciola hepatica infections in sheep with treiclabendazone.Vet. Rec. 80, 218224.

Chiks, B.F. Coverdale, O.R., \& Jackson, A.R.B (1980). Production effects of liver fluke (Fasciola hepatica) infection in beef cattle .Australia Veterinary Journal, 56, and 588592.

Esenin, F. (1984) .Triclabendazon - a new anthelmintic for the treatment of immature and mature Fasciola gigantic and Fasciola hepatica in sheep. Veterinary Clinician February/March, pg10-12

Hawkins, C.D. \& Morris R.S (1978). Depression of productivity in sheep infected with Fasciola hepatica .Veterinary Parasitology. 4, 341-351.

Ministry of Agriculture (MoA) (2012).Annual report on agricultural productivity in Kenya: Author

Reid, J.F.S., \& Armour, J. (1978).An economic appraisal of helminthic parasites in sheep. Vet. R.C.102, 407.

Ross, J. G. (1970). The economics of Fasciola hepatica infections in cattle British Veterinary Journal. Volume 126: XIII-XV.

Smeal, M.G., \& Hall, C.A. (1983); the activity of tricabendazole against immature and adult Fasciola hepatica infections in sheep. Australia Veterinary Journal 60: 329331. 
Paul, M., M, N.V., K, V.N., \& Ooko, L.A. (2016). The Socio Economic Impact of Facioliasis Disease in Nandi Central District, Kenya. Archives of Business Research, 3(4), 26-32.

Strong, M.B. \& Boray, J.C (1983). Antihelmintics and their impact on the pathology of Fasciola Spp. in sheep and cattle. Australia. Abstr. 10th international. WAAAVP. Conf. Perth, August 18-20.

Torgerson, P., Claxton J. (1999). “Epidemiology and control” in Dalton JP. Fascioliasis.

Wallingford, Oxon, UK: CABI Pub. Pp 113-149. 